See discussions, stats, and author profiles for this publication at: https://www.researchgate.net/publication/296443681

\title{
Grief, After Death Communications and Childhood Abuse: Two Substance Use
} Case Reports

Article in Journal of Addiction Research \& Therapy · March 2016

Dol: 10.4172/2155-6105.1000265

CITATIONS

0

3 authors, including:

Sam Banbury

London Metropolitan University

18 PUBLICATIONS 45 CITATIONS

SEE PROFILE
READS

267

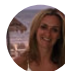

Jo Lusher

University of the West of Scotland, London Campus

54 PUBLICATIONS 546 CITATIONS

SEE PROFILE

Some of the authors of this publication are also working on these related projects:

Project Dentists' experiences of dentally anxious patients in a specialist setting: An interpretative phenomenological analysis. View project

Project The use and abuse of e-cigarettes View project 


\title{
Grief, After Death Communications and Childhood Abuse: Two Substance Use Case Reports
}

Samantha Banbury ${ }^{\star}$, Joanne Lusher and Catherine Athanasiadou-Lewis

School of Psychology, London Metropolitan University, UK

*Corresponding author: Samantha Banbury, School of Psychology, London Metropolitan University, London, UK, Tel: +44 (0)20 7423 0000; E-mail: s.banbury@londonmet.ac.uk

Received date: Jan 11, 2016; Accepted date: Feb 04, 2016; Published date: Feb 11, 2016

Copyright: ( 2016 Banbury S, et al., This is an open-access article distributed under the terms of the Creative Commons Attribution License, which permits unrestricted use, distribution, and reproduction in any medium, provided the original author and source are credited.

\begin{abstract}
The following two case reports discuss the effect of grief on their drug-use behaviour. Both case descriptions of substance use disorders are comorbid with depression and/or an anxiety-related disorder. Case 1 and 2 have a history of childhood sexual and physical abuse and report multiple drug relapses as a consequence of unresolved grief associated with the abuse. The maladaptive grief process of case 1 and 2 had presented itself in the subjective belief of having after death communications with the deceased. The application of cognitive behavioural techniques driven by psychodynamic insights, revealed a relationship between the grief experienced, childhood abuse and the use of prescription medication and illicit drug use. The case descriptions of grief are discussed in the context of substance misuse, mental health and the triggers associated with relapse in an attempt to further our understanding of substance abuse and therapy.
\end{abstract}

Keywords: Grief; After death communications; Substance misuse; Recovery; Cognitive behaviour therapy

\section{Introduction}

The foundations to our understanding of the intra psychic processes of grief have been originally laid by Freud in his discussion of 'mourning and melancholia', followed by subsequent psychodynamic approaches on the mechanisms of defence, object relations and unconscious conflicts $[1,2]$. Contemporary psychological approaches on bereavement and loss, including cognitive and relational theories, rely heavily on prototypic psychodynamic insights such as the role of transference, internalisation, affective experience, mental representation and the meaning of loss. According to Smith [3], grief is a natural emotional reaction to the loss of a significant other [4] contends that the grieving process has five stages: shock-denial, bargaining, anger, depression and acceptance. Alternatively, views grieving as periods of sadness rather than a prolonged stage process, where feelings of sadness become less intense over time [5]. Developing four trajectories of grief, suggested that resilience is a human response to grief and following a period of a few days to a few weeks, the bereaved continue to function accordingly in their daily lives [5]. Winnicott's [6] theory of transitional objects, in relation to loss, suggests that the bereaved may select a transitional object to soothe their pain from the absence of their loved one. Eventually the mourner should be able to let go of their objects, as they develop the ability to internalize the memory and meaning of their loss [7].

Accordingly, a transitional object is symbolic of a special bond or relationship between a mother and her baby. A representational object will be selected in order to provide comfort and security as an inner representation of the mother [6]. Substance misuse could be construed as a transitional object for the mourner, in as much as the substance serves to soothe overwhelming affect in the same way the maternal object relation would. The mourner's ability to maintain an inner representation of the deceased object should determine their capabilities for self-soothing in the same fashion a child internalises the maternal representation. Eventually a child will build and strengthen their ability to maintain an internal representation and their object will become meaningless [7].

However, substance abuse as a transitional object may present with certain challenges due to its 'numbing' reciprocal properties, which in turn disrupt the healing process when the mourner finds themselves dependent on that object-relation. So instead of letting go of the transitional object and resorting to the original mental representation of the soothing object relation, the mourner finds themselves dependent on the substance. From an object relations perspective, it could be further argued that the choice of a substance as a transitional object symbolically corresponds to an unavailable maternal representation, thus producing dissociative effects from the pain of the rejecting self-object [8]. As a result, grief can become a complicated and unresolved process that quite often leads to depression.

According to [9], approximately $35 \%$ of the bereaved meet diagnostic criteria for a depressive disorder during the grieving process and approximately $20 \%$ of those continue to experience abnormally intense grief [10]. DSM-5 distinguishes grief from a Major Depressive Episode [11]. Whilst both include feelings of sadness and loss, MDE is more persistent and focuses less on a specific concept. Unresolved grief can cause significant distress or impairment $[11,12]$.

Jacobs and Stroebe, and Stroebe and Hansson, posit that pathological grief is a result of a death, which is sudden and unexpected, and this is not always dependent upon the level of social support provided $[12,13]$. DSM-5 refers to "Persistent Complex Bereavement Disorder categorized by a persistent yearning for the deceased, intense sorrow and pain, a preoccupation with the deceased and the circumstances of the death" [11]. Understanding the role that grief plays in the addiction process is critical for assisting those with dependency issues. Mark and Faude theorise that drugs substitute a chemical reaction in place of experiences and that these chemically induced experiences can block the impact of other, real and significant 
external events. The client with a substance abuse disorder will therefore have a "tremendously impoverished and impaired capacity to experience, and traditional psychotherapy might have to be augmented with techniques that focus on increasing a client's ability to experience" [14].

Certain reminders, such as anniversaries and birthdays, can form part of the substance misusers grieving process and act as triggers for drug relapse. Reducing opiates often sensitises the emotions of substance misusers, where emotions (and grief) become overwhelming and often result in relapse. Ultimately, this can perpetuate and maintain drug using behaviour and the grief that triggered it. For some, the period of anhedonia following drug and alcohol abstinence can precipitate a relapse further [15]. Those with a substance misuse problem, who remain abstinent, may relapse or be primed to return to drug use as a consequence of these triggers, drug cues and cravings. The dopaminergic activation in the mesolimbic pathway becomes activated by the presence of a pleasurable or aversive stimulus, which determines the motivational state of wanting the drug [16]. The Incentive Sensitization Theory of Addiction postulates that addiction is the result of sensitisation of the mesolimbic pathway [17]. The continued use of drugs can result in drug cues becoming more salient. Leading to intense cravings and possible relapse. In many ways this explains the unconscious processes involved in wanting the drug associated with drug cues and relapse. According to Zilverstand, Parvaz, Moeller, \& Goldstein, neuroimaging provides a means of understanding the neurobiological mechanisms involved in cognitive interventions in substance misuse [18]. Their study revealed that the hypoactive prefrontal regions can be regulated via cognitive approaches. Therefore, mindfulness based CBT in many ways is combining both conscious and unconscious factors involved in substance misuse. Bajaj, Gupta and Pande suggest that mindfulness is associated with self-esteem and resilience [19]. Employing an integrative approach, based on relational and mindfulness based cognitive behavioural interventions, highlights the importance of negotiating and challenging old shame-related beliefs; exploring and updating meanings about loss; and modifying behaviours associated with the significant other and drug use behaviour [20-25].

As the following two cases illustrate, shame and guilt appear central to the maintenance of the disorder and grief and childhood abuse has played a significant role in their psycho-pathology. Indeed, exposure to traumatic experiences in childhood, has been linked to substance abuse disorders, Posttraumatic Stress Disorder (PTSD) and other mood-related psychopathologies previously [26,27]. Moreover, in one study, high rates of lifetime dependence on various substances were found $39 \%$ alcohol, $34.1 \%$ cocaine, $6.2 \%$ heroin/opiates, and $44.8 \%$ marijuana) and substance use, particularly cocaine, significantly correlated with levels of childhood physical, sexual, and emotional abuse as well as current PTSD and complex trauma symptoms [28].

\section{Cases and Methods}

Case 1 and 2 (consented anonymised clients) had experienced multiple bereavements and were victims of childhood physical and sexual abuse. Both were psychiatrically assessed prior to attending a drug maintenance programme and cognitive behavioural therapy, and had been diagnosed with depression and/or an anxiety disorder. Further, the cases had not been diagnosed with Post Traumatic Stress Disorder (PTSD) but the presence of trauma was established. Case 1 is a 44 year old heterosexual married female who is employed by a large London company. She has a long history of poly substance abuse commencing at the age of 12 . Drugs included the intravenous use of heroin, crack inhalation and non-prescription diazepam. Case 1 has undergone approximately 4 in-patient detoxifications followed by drug rehabilitation. Following each detoxification and rehabilitation, case 1 relapsed within 6 months of treatment. She currently attends a drug maintenance programme and is prescribed methadone and diazepam. This is supported with mindfulness based cognitive behavioural therapy and psychosocial support.

\section{Case 1 reported}

An elderly couple used to babysit my brother and I. The old man, when I was about 5 years old was sexually abusing me. My brother never said anything but I know he was abused to. This happened regularly. I started running away and bunking-off [truanting] school when I was 12 years old. When I was 13 I was using heroin. It felt like all my troubles just went. When I told my dad what had happened he punched me and I fell down the stairs. That reaction has lived with me. The old man [alleged abuser] was a dirty pervert but who I thought loved me $\{\mathrm{dad}\}$, his reaction destroyed me. So I had to live with it and never discussed it until I attended clinic. When my father died I never got over it, all I wanted him to do was say he loved me, that he believed me. What I haven't mentioned is that every time I see dad in my dreams, I wake up angry. He blames me and I feel dirty. I don't feel accepted or loved. Then I turn the anger inwards and use. I'm angry because he hasn't forgiven me'.

Case 2 is a 43 year old heterosexual male who is currently unemployed and lives with his girlfriend. Case 2 has a long history of poly-substance abuse commencing at the age of 17 . Drugs included the intravenous use of heroin, crack inhalation and non-prescription diazepam. Case 2 has undergone approximately 5 in-patient detoxifications followed with drug rehabilitation. Following each detoxification and rehabilitation, case 2 relapsed within 4 months of treatment. He currently attends a drug maintenance programme and is prescribed methadone and diazepam. This is supported with mindfulness based cognitive behavioural therapy and psychosocial support.

\section{Case 2 reported}

'I feel angry at my wife and then guilt for hating her. This is not the hate I have because they have died but my hate for what they did to me. My wife was very abusive. She was an alcoholic but I was a heroin user and yet I was the problem. Trust me her behaviour was violent not mine. She used to steal off me, go out to clubs and do God knows what. She died in an accident. Turned out she was seeing another bloke anyway. When she died her family blamed me, because I was the 'smack head'. I was the problem. I've always had problems sleeping, in some ways that's why I prefer opiates and Benzo's [Benzodiazepam] as it helps me get off to sleep. But they don't always help or I wake up in the early hours and can't sleep after. In them cases I smoke cannabis just to relax me as I have an anxiety disorder. My household was run by an abusive father and my mother was very cold. I was taken into foster care a few times with different families. I had run away a few times and when I discovered heroin it was the best thing that had ever happened to me. I was asleep and yet I was awake. The Mrs used to come towards me and I felt this heavy weight on my chest, then wake up in a panic. She presented as a manifestation, so whilst I couldn't see her, I knew it was her. She didn't say anything. Then I used drugs. After a while I didn't want to go to sleep because this was so awful so I started using crack to stay awake.' 
Case 1 and 2 were receiving 20, 60 minute weekly CBT sessions. The application of mindfulness based cognitive behavioural techniques driven by psychodynamic insights revealed a relationship between the grief, childhood abuse and the use of prescription medication and illicit drug use. Both cases discussed how both a lack of closure and guilt associated with the death of a significant other were triggers to a drugs relapse, often upon waking. Unresolved grief was being suppressed by drugs in order to subdue the emotions of sadness, loss, guilt and anger experienced. Similarly to the findings of Tarter, case 1 and 2 also experienced difficulties in expressing their emotions efficiently in a social context, particularly negative emotions. By identifying the grief-related cognitions and working with the intrapsychic processes has therapeutically guided the cases aim towards recovery $[22,23,29,30]$.

According to Lawson, Back, Hartwell and Moran-Santa Maria, exposure to traumatic events is common among individuals with substance use disorders [31]. The Self- medicating hypothesis as postulated by Khantzian, suggests that the development of addictive behaviours results from repeated substance misuse in order to minimise the level of distress experienced [32]. Indeed, case 1 and 2's childhood abuse had caused significant distress centring on a lack of closure and a need for acceptance, and resulted in self-medicating with poly-substance use. Both cases discussed issues of self-hatred and lack of forgiveness. Anger had been directed at a significant other who didn't believe them when they tried to discuss their childhood abuse. For example, Case 2's crack binges had resulted in a stimulant based psychosis and sleep paralysis. Here, unresolved issues coupled with sleep deprivation and the misuse of drugs, was affecting this case 2'sability to work through his anger and grief.

The cases kept a dream journal and drug diary to assist them in understanding their dreams and grief in the context of substance use. Case 1 believed that she was experiencing after-death communications with her father. As the therapy progressed, these messages from her deceased father have become what she describes as less negative. According to Neenan and Dryden, distortions in thinking result from underlying negative core beliefs, which often stem from childhood [33]. Changes were witnessed in case l's beliefs and cognitions resulting in a more positive sense of self as a result of cognitive restructuring and relational interventions like containment and transference interpretations. Discussing her beliefs in this context has not only developed the therapeutic relationship, but has greatly assisted case 1's understanding of her drug using behaviour as a defence against affective experience. The therapeutic arena has provided both cases with a means of expressing their thoughts and challenging their self-defeating beliefs. Those interventions have encouraged them to recognize how their emotional distress was not allowed conscious experiencing due to their punitive rules for living and insecure object relations, resorting to substances to numb difficult emotions and thus perpetuate their pathology.

Cases 1 and 2 received 12 weekly CBT sessions and are beginning to report a greater motivation with their life course. The misuse of their prescription drugs is still apparent but to a lesser degree. Exploring interpersonal cognitions and core beliefs of the cases has provided a means for developing the therapeutic tools necessary to encourage and support them during times where a potential trigger, owing to grief, has precipitated a relapse.

\section{Discussion}

The cognitive developmental model of substance abuse and the Padesky and Mooney's five part generic cognitive model for situationlevel formulation have been employed to support clients with individual treatment needs [20,24,34]. Further, relapse prevention training, communication skills training and cognitive behavioural mood management training have been included in the cases therapeutic treatment programme [35-37].

Whilst the dual process model as postulated by Stroebe and Schut's acknowledges varying grief responses including loss orientation and loss restoration, in the context of substance misuse this process tended to precipitate a drugs relapse [38]. The presence of guilt, anger, shame and depression experienced by case 1 and 2 had determined how they have adjusted to grief. When dwelling on components of their loss, the use of drugs has in part modulated case 1 and 2's affect associated with helplessness and hopelessness [39]. When case 1and 2 tried to manage their stressors (restoration stressors) the guilt experienced by them was associated with them getting on with their lives. This became linked to feelings of helplessness associated with the death of a significant other.

Case 1 felt she could achieve resolution by 'making contact with the deceased' (due to difficulties with separation and loss) whereas case 2 believed he could achieve resolution if he avoided any contact with his deceased wife. Here, the cognitive dissonance associated with the loss of a significant other had become perpetuated in their drug using behaviours. This was reflective of the cases inability to integrate the reality of their loss into their existing mental representations of themselves [40]. These negative self-appraisals coupled with the use of avoidant strategies became perpetuated in their drugs use.

Personality traits including low self-esteem and impulsivity were commonly observed among case 1 and 2 . The cases problem-solving skills centred on the belief that drugs regulate and control feelings and thoughts. It appeared that both cases had not been afforded an opportunity to discuss their feelings, beliefs and thoughts surrounding their childhood abuse with the perpetrator or non-perpetrating carer. In this report, unanswered questions were: Why did you let this happen? Why didn't you believe me? Why didn't you stop it? Their core beliefs underlying these questions included for example, 'I am dirty', 'I am disgusting', and 'I am unlovable. Feelings of guilt and anger had become supressed by using illicit drugs or misusing prescription medication. Whilst feelings of guilt, shame, and hopelessness are traditional components of grief, Case 1 and 2 appeared to be experiencing complicated grief which they attributed to adverse life events, including childhood abuse. Vanderwerker, Jacobs, Parkes and Prigerson examined the relationship between childhood separation anxiety and complicated grief, PTSD, anxiety and depression among 283 recently bereaved individuals [41]. Whilst childhood anxiety disorder was significantly associated with complicated grief, interestingly no such relationship existed between childhood separation anxiety, PTSD, anxiety and depression. Since the cases in this discussion have experienced childhood poly-victimisation, it would seem that the high levels of trauma symptoms experienced had compounded their guilt, shame, and hopelessness in the context of grief and perceived after death communications [42].

Nonetheless, these case discussions may not be typical of a larger drug using population. Further, there are risks of false memory and incorrect accounts of their grief-related experiences, especially as amphetamine use has been shown to increase errors in episodic memory retrieval [43]. The use of psychoactive drugs may impact 
encoding processes, possibly resulting in the creation of false memories [44]. Case 1 and 2 may displace responsibility by justifying their drug use behaviour to spiritual matters. For example, distorted cognitive beliefs, including for example, 'I can talk to dad when I'm out of it', 'I can resolve my problems when I use drugs' or 'I can avoid my Mrs when I stay awake on drugs. Therefore, when case 1 and 2 used their medication incorrectly, or used illicit drugs on top, this resulted in the subjective belief of having after-death communications, a manifestation of unresolved grief. Ultimately these behaviours were attempts at self-medicating their unresolved childhood abuse issues.

\section{Conclusion}

Anger, guilt and loss of control in the context of lack of closure were often indicated by the cases in this report and processed further using empathy, containment and transferential interpretations within the therapeutic relationship. Case 1 and 2's unresolved childhood sexual and physical abuse conflicts often felt out of control and needed closure in terms of self-acceptance before they could begin to work through their grief or embrace their life course. Whilst traditional CBT places emphasis on cognitive restructuring and behavioural activation as the main avenues to recovery from complex grief, there is still a clear lack of focus on emotional and intra-psychic processes inherent in such pathological states. Esma et al. claim that the main components of CBT for complicated grief typically consist of (a) exposure to avoided bereavement-related cues;(b) cognitive restructuring of lossrelated negative cognitions; and/or (c) behavioural activation to counter inactivity and behavioural withdrawal [45]. Very little is being said however, about the value of exploring and processing affective experience in the therapeutic relationship, which is central to the recovery process of individuals with substance abuse disorders and grief [46]. It would be thus important to emphasize that cognitive behavioural interventions added value to the treatment of the above cases when guided and driven by psychodynamic insights on intrapsychic processes such as unconscious fantasy and mechanisms of defences [2]. When case 1 and 2 used drugs, they believed that they had experienced after-death communications as a manifestation of unresolved grief. Therefore, encouraging them to discuss spiritual beliefs in the context of their drug using behaviour provided them with an alternate means of understanding their treatment needs. Mindfulness was integrated into their treatment programme in the context of respecting the cases beliefs surrounding life and death issues, from a cultural perspective. This is critical for the development of more efficient treatment modalities where overall improvements in treatment compliance and psychosocial functioning are imperative. We hope that the discussions presented within this report provide a foundation in which to conduct future research that will bring us closer to a much needed tailored recovery programme for these recovering substance users.

\section{Conflict of Interest}

The authors declare no conflict of interest. All procedures followed were in accordance with the ethical guidelines, including adherence to the legal requirements in the UK. Informed consent was obtained from the cases in this discussion. The cases did not report any distress as a consequence of this 'study'. Further, all ethical guidelines were in accordance with the British Psychological Society (BPS) code of ethics and conduct.

\section{References}

1. Freud S (1917) Mourning and Melancholia. The Standard Edition of the Complete Psychological Works of Sigmund Freud 15, On the History of the Psycho-Analytic Movement, Papers on Metapsychology and Other Works pp: 237-258.

2. Fenichel O (1946) The psychoanalytic theory of neurosis. New York: Norton.

3. Smith MJS (2012) Coping with Grief and Loss.

4. Kubler-Ross K (1969) On Death and Dying, Routledge.

5. Bonanno GA, Wortman CB, Lehman DR, Tweed RG, Haring M, et al. (2002) Resilience to loss and chronic grief: a prospective study from preloss to 18-months postloss. J Pers Soc Psychol 83: 1150-1164.

6. Winnicott DW (1965) "Ego distortion in terms of true and false self". The Maturational Process and the Facilitating Environment: Studies in the Theory of Emotional Development, International Universities Press, New York.

7. Berzoff J (2003) Special issue on end of life care, Smith College Studies in Social Work p: 73.

8. Kohut H (1977) The restoration of the self. New York: International Universities Press

9. Zisook S, Shuchter SR (1991) Early psychological reaction to the stress of widowhood. Psychiatry 54: 320-333.

10. Gelder M, Gath D, Mayou R, Cowen P (1996) Oxford Textbook of Psychiatry. Oxford, New York, Melbourne. Oxford University Press.

11. American Psychiatric Association (2013) Diagnostic and Statistical Manual of Mental Disorders, DSM-5, Arlington, American Psychiatric Publishing, Washington.

12. Stroebe M, Schut H, Stroebe W (2007) Health outcomes of bereavement. Lancet 370: 1960-1973.

13. Jacobs S (1993) Pathologic grief: Maladaptation to loss. Washington, DC. American Psychiatric Press.

14. Mark D, Faude J (1995) Supportive-expressive therapy of cocaine abuse, Dynamic therapies for psychiatric disorders. New York.

15. Garfield JB, Lubman DI, Yücel M (2014) Anhedonia in substance use disorders: a systematic review of its nature, course and clinical correlates. Aust N Z J Psychiatry 48: 36-51.

16. Gardner EL, Ashby CR Jr (2000) Heterogeneity of the mesotelencephalic dopamine fibers: Physiology and pharmacology. Neurosci Biobehav Rev 24: 115-118.

17. Robinson TE, Berridge KC (1993) The neural basis of drug craving: an incentive-sensitization theory of addiction. Brain Res Brain Res Rev 18: 247-291.

18. Zilverstand A, Parvaz MA, Moeller SJ, Goldstein RZ (2016) Cognitive interventions for addiction medicine: Understanding the underlying neurobiological mechanisms. Prog Brain Res 224: 285-30.

19. Bajaj B, Gupta R, Pande N (2016) Self-esteem mediates the relationship between mindfulness and well-being. Personality and Individual Differences 94: 96-100.

20. Beck AT, Wright FD, Newman CF, Liese BS (1993)Cognitive Therapy of Substance Abuse. London. Guilford Press.

21. Horowitz MJ, Bonanno GA, Holen A (1993) Pathological grief: diagnosis and explanation. Psychosom Med 55: 260-273.

22. Kavanagh DJ (1990) Towards a cognitive-behavioural intervention for adult grief reactions. Br J Psychiatry 157: 373-383.

23. Gluhosky VL (1995) A cognitive perspective on bereavement: Mechanisms and treatment. J Cog Psychotherapy: Internat 9: 75-80.

24. Liese BS, Franz RA (1996) Treating substance use disorders with Cognitive Therapy: Lessons learned and implications for the future, Frontiers of Cognitive Therapy, Guilford Press, New York.

25. Neimeyer R A (1999) Lessons of loss: A guide to coping, McGraw-Hill, New York.

26. Leskela J, Dieperink M, Thuras P (2002) Shame and posttraumatic stress disorder. J Trauma Stress 15: 223-226. 
Citation: Banbury S, Lusher J, Lewis CA (2016) Grief, After Death Communications and Childhood Abuse: Two Substance Use Case Reports. J Addict Res Ther 7: 265. doi:10.4172/2155-6105.1000265

Page 5 of 5

27. Arnow BA (2004) Relationships between childhood maltreatment, adult health and psychiatric outcomes, and medical utilization. J Clin Psychiatry 65: 10-15.

28. Khoury L, Tang YL, Bradley B, Cubells JF, Ressler KJ (2010) Substance use, childhood traumatic experience, and Posttraumatic Stress Disorder in an urban civilian population. Depress Anxiety 27: 1077-1086.

29. Tarter RE (2005) Psychological Evaluation of Substance Use Disorder in Adolescents and Adults. Clinical textbook of Addictive Disorders, Guilford Press, New York.

30. Rando TA (1988) Grieving: How to go on living when someone you love dies, Lexington Books, Lexington, USA.

31. Lawson KM, Back SE, Hartwell KJ, Moran-Santa Maria M, Brady KT (2013) A comparison of trauma profiles among individuals with prescription opioid, nicotine, or cocaine dependence. Am J Addict 22: 127-131.

32. Khantzian EJ (1977) The Self-Medication of Substance Misuse Disorders: A Reconstruction and Recent Applications. Harvard Review of Psychiatry 4: 231-244.

33. Neenan M, Dryden W (2002) Life Coaching. A Cognitive-Behavioural Approach, Routledge, Taylor \& Francis Group, London and New York.

34. Padesky CA, Mooney KA (1990) Clinical tip: Presenting the Cognitive Model to Clients. International Cognitive Therapy Newsletter 6: 13-14.

35. Marlatt GA, Gordon JR (1985) Relapse Prevention: Maintenance Strategies in the Treatment of Addictive Behaviours. New York, Guilford Press.

36. Miller WR, Westerberg VS, Harris RJ, Tonigan JS (1996) What predicts relapse? Prospective testing of antecedent models. Addiction 91: 55-172.

37. Monti PM, Colby SM, Barnett NP, Spirito A, Rohsenow DJ, et al. (1999) Brief intervention for harm reduction with alcohol-positive older adolescents in a hospital emergency department. J Consult Clin Psychol 67: 989-94.

38. Strobe M, Schut H (1999) The dual process model of coping with bereavement: Rationale and description. Death Stud 23: 197-224.

39. Dodes LM (1990) Addiction, helplessness, and narcissistic rage. Psychoanal 59: 398-419.

40. Boelen PA, Hout MA, van den, Bout, et al. (2006) A cognitivebehavioural conceptualization of complicated grief. Clin Psychol 13:109-128.

41. Vanderwerker LC, Jacobs SC, Parkes CM, Prigerson HG (2006) An exploration of associations between separation anxiety in childhood and complicated grief in later life. J Nerv Ment Dis 194: 121-123.

42. Finkelhor D, Ormrod RK, Turner HA (2007) Poly-victimization: a neglected component in child victimization. Child Abuse Negl 31: 7-26.

43. Ballard ME, Gallo DA, de Wit H (2014) Amphetamine increases errors during episodic memory retrieval. J Clin Psychopharmacol 34: 85-92.

44. Ballard ME, Gallo DA, de Wit H (2012) Psychoactive drugs and false memory: comparison of dextroamphetamine and $\hat{\mathrm{I}}^{\prime}-9$ tetrahydrocannabinol on false recognition. Psychopharmacology (Berl) 219: 15-24.

45. Eisma MC, Boelen PA, van den Bout J, Stroebe W, Schut HA, et al. (2015) Internet-Based Exposure and Behavioral Activation for Complicated Grief and Rumination: A Randomized Controlled Trial. Behav Ther 46: 729-748.

46. Cheyne J (2003) Sleep Paralysis and the Structure of Waking-Nightmare Hallucinations. Dreaming 13: 163-179. 